\title{
Singuagens
}

\section{REALIZAÇÃO LÓGICA DA LINGUAGEM EM NOTÍCIAS SOBRE O IMPEACHMENT DA PRESIDENTE AFASTADA DILMA ROUSSEFF: UMA ANÁLISE DE PROJEÇÃO NO COMPLEXO ORACIONAL}

\author{
Elisane Scapin Cargnin (UFSM) \\ Gessélda Somavilla Farencena (UFSM)
}

RESUMO: O presente trabalho, por meio de um estudo-piloto, apresenta uma análise acerca da realização lógico-semântica da linguagem em duas notícias sobre o impeachment da Presidente afastada Dilma Rousseff, a partir da análise do complexo oracionall, mais especificamente da projeção. O estudo está alicerçado em princípios da Gramática Sistêmico-Funcional (HALLIDAY; MATTHIESSEN, 2014), especificamente o modo lógico da metafunção ideacional da linguagem. Além desse princípio, focalizamos nossa análise em Martin e White (2005) no que diz respeito ao engajamento com destaque à atribuição a partir da análise de processos verbais. Como resultados, constatamos de forma mais acentuada a interdependência hipotática. As orações são projetadas por processos verbais e trazem marcas de autoria relacionadas às vozes não autorais, como é o caso do processo verbal alegar. Também foram usados pelos autores processos neutros, por exemplo, o processo verbal dizer quando os autores das notícias queriam apenas relatar a informação ou fato.

PALAVRAS-CHAVE: Realização lógica. Notícias. Projeção. Complexo oracional.

ABSTRACT: The present work, through a pilot study, presents an analysis of the logico-semantic realization of the language in two reports about the impeachment of the President Dilma Rousseff, from the analysis of the sentence complex, more specifically the projection. The study is based on principles of the Systemic-Functional Grammar (HALLIDAY; MATTHIESSEN, 2014), specifically the logical mode of the ideational metafunction of language. In addition to this principle, we focus our analysis on Martin and White (2005) regarding engagement with emphasis on attribution from the analysis of verbal processes. As results, we find a more pronounced hypothetical interdependence. The prayers are projected by verbal processes and bear authorial marks related to non-authoritative voices, as is the case of the verbal verdict. Neutral processes were also used by the authors, for example, the verbal process to say when the authors of the news wanted only to report the information or fact.

KEYWORDS: Logical realization. News. Projection. Prayer complex.

\section{INTRODUÇÃO}

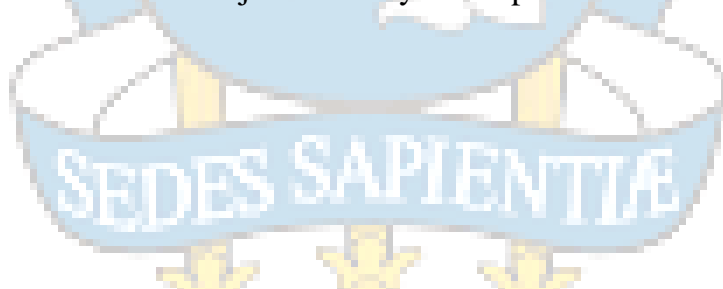

Halliday e Matthiessen (2014), quando investigam como as orações são articuladas por meio de relações que formam complexos oracionais, apresenta os complexos construídos de duas maneiras. Para eles, são dois sistemas básicos que constroem uma oração: o grau de interdependência e as relações lógico-semânticas.

A interdependência (taxe) promove a produção de diferentes complexos oracionais, um possui o status (parataxe), em que um continua o outro; já o outro possui o status desigual (hipotaxe), uma vez que a relação ocorre entre um elemento que depende e outro que 


\section{Singuagens}

domina. Também, segundo Halliday e Matthiessen (2014), para marcar as orações no discurso direto, usamos numerais e, no discurso indireto, letras gregas. No que diz respeito ao sistema lógico-semântico, Halliday mostra que existe um conjunto de diferentes relações lógicosemânticas, que podem ocorrer entre um elemento primário e um secundário de um nexo oracional tanto por parataxe quanto por hipotaxe.

Neste trabalho, temos como objetivo verificar a realização lógica da linguagem em duas notícias sobre o impeachment da Presidente afastada Dilma Rousseff, a partir da análise do complexo oracional, mais especificamente da projeção. Para atender ao objetivo, partimos do tema: como ocorrem os processos de atribuição em duas notícias de jornais online tendo em vista a relação lógico-semântica de projeção.

Com relação à organização deste texto, inicialmente, apresentamos objetivo do trabalho, na sequência, resumidamente, a seção de revisão da literatura. Em seguida, explicamos como desenvolvemos o trabalho na seção da metodologia e, por fim, a discussão e interpretação dos dados. Na próxima seção, apresentamos brevemente o complexo oracional.

\section{REVISÃO DA LITERATURA}

\subsection{Gramática Sistêmico-Funcional}

A Linguística Sistêmico-Funcional caracteriza-se como uma teoria semiótica, porque se preocupa com a linguagem em todas as suas manifestações. Além disso, tenta desvendar como, onde, por que e para que o homem usa a linguagem. Essa interação entre linguagem e sociedade leva a LSF para um contexto diferente do contexto tradicional da linguística. Na linguística tradicional, partimos da estrutura, da forma, separada do uso ou do significado, portanto, não da linguagem como um todo (BARBARA; MACÊDO, 2009, p.90). Para Halliday e Matthiessen (2014), a linguagem é concebida como um sistema de escolhas e é utilizada em um meio social em que o indivíduo desempenha papéis sociais. Para os autores, é possível organizarmos a linguagem "acima" e "abaixo" da oração, além de olharmos o seu próprio nível (HALLIDAY; MATTHIESSEN, 2014). Para esta análise, dedicamo-nos especificamente no modo lógico da metafunção ideacional da linguagem. Na sequência, apresentamos noções do complexo oracional.

\section{Linguagens \& Cidadania, v. 19, jan./dez., 2017.}




\section{Linguagens \& Cidadania}

\subsubsection{O complexo oracional}

De acordo com Halliday e Matthiessen (2014, p.438), na parataxe, todas as orações ligadas por uma relação lógico-semântica são independentes (status de igualdade) e na hipotaxe, ocorre a interdependência, em que uma é a dominante e a(s) outra(s) é (são) dependente(s) (status desigual). Segundo os autores, "a escolha entre parataxe e hipotaxe caracteriza cada relação entre duas orações" $\left(2014\right.$, p.441 $\left.{ }^{1}\right)$. Na figura abaixo, segue a representação sistêmica proposta em Halliday e Matthiessen (2014).

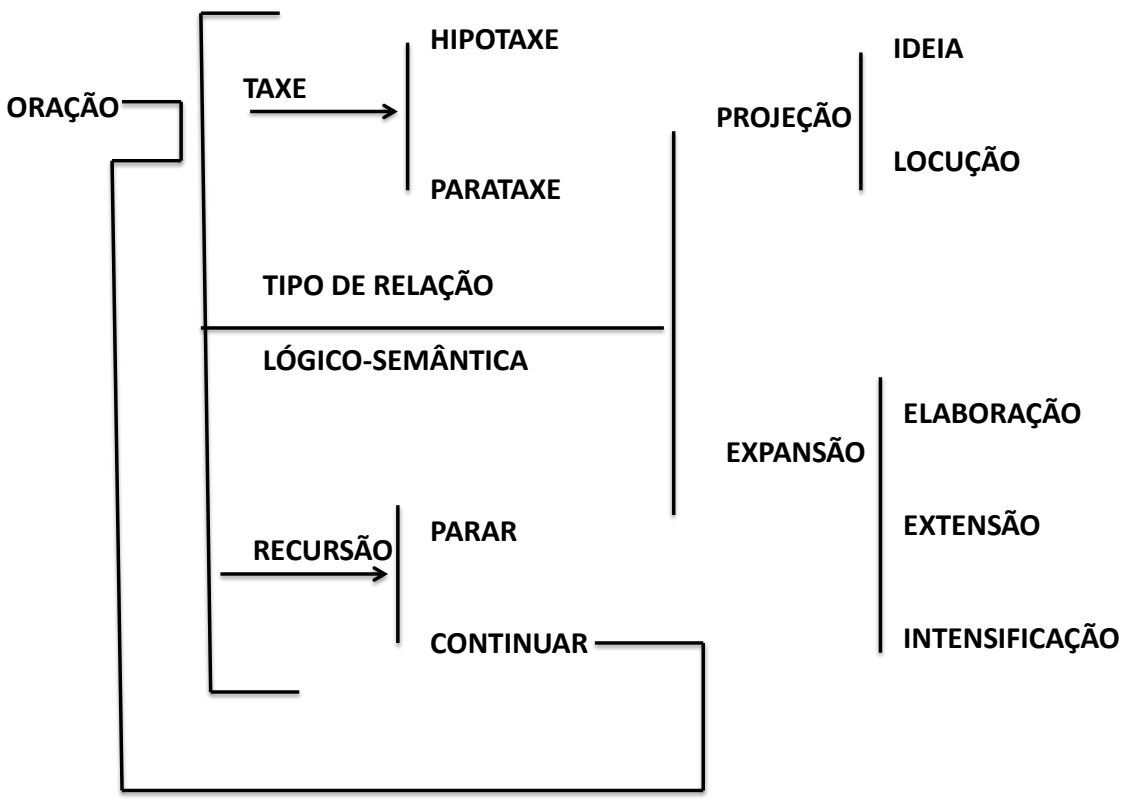

Tradução de Halliday e Matthiessen (2014, p.438)

Figura 1- Representação sistêmica proposta em Halliday e Matthiessen (2014).

Então, para Halliday e Matthiessen (2014), os complexos são definidos por relações gerais. A parataxe é a ligação de elementos de mesmo nível, já que estão em lugares diferentes no complexo e isso não altera o sentido. "Em princípio, a relação paratática é

${ }^{1}$ As traduções são de responsabilidade das autoras.

Linguagens \& Cidadania, v. 19, jan./dez., 2017. 


\section{Singuagens}

logicamente simétrica e transitiva" (HALLIDAY; MATTHIESSEN, 2014, p. 452). Esses componentes, sejam orações, grupos ou sintagmas, têm o mesmo status.

Já a hipotaxe corresponde à ligação de elementos de estado desigual e "o elemento dominante é livre, mas o elemento dependente não é." (HALLIDAY; MATTHIESSEN, p. 452, 2014). Ao contrário, a relação hipotática é logicamente não simétrica e não transitiva, uma vez que a inversão na ordem dos elementos provoca alteração de sentido. Normalmente, as estruturas hipotáticas e paratáticas combinam no mesmo complexo oracional (p. 456).

De acordo com Halliday e Matthiessen (2014), a estrutura hipotática pode ser representada com letras gregas e a oração dominante é $\alpha\left(\alpha^{\wedge} \beta\right.$ ou $\left.\beta^{\wedge} \alpha\right)$, em que os elementos estão em dependência. Já a estrutura paratática é identificada por números cardinais em ordem crescente $\left(1^{\wedge} 2\right)$. Halliday e Matthiessen (2014) também aprese ntam "um mecanismo semogênico, denominado encaixamento (embedding)" (HALLIDAY e MATTHIESSEN, 2014 p. 491) que é representado na análise por [[ ]]. “O encaixamento é a "mudança de ranking" por que uma oração ou frase passa a funcionar dentro de uma estrutura ou de um grupo" (HALLIDAY; MATTHIESSEN, 2014, p.491).

Assim como em orações paratática e hipotática combinam-se em complexos oracionais, um elemento encaixado pode ser também uma expansão ou uma projeção. "O significado de uma oração encaixada, que está funcionando como uma expansão é essencialmente para definir, delimitar ou especificar" (HALLIDAY; MATTHIESSEN, 2014, p. 493). Na expansão, relacionam-se fenômenos que fazem parte da mesma ordem experiencial; já na projeção, relaciona-se um fenômeno a outro de ordem superior da experiência (HALLIDAY; MATTHIESSEN, 2014).

De acordo com Halliday e Matthiessen (2014), na expansão, a oração secundária expande a oração primária por meio de três diferentes operações: elaboração, extensão e intensificação. A elaboração representada pela notação $(=)$ pode significar "dizer em outras palavras", isto é, elaborando seu conteúdo por meio de especificação ou descrição. A extensão que se compreende como "adicionar de ideia nova" e é identificada pela notação $(+)$, uma oração estende o sentido da outra, pois adiciona algo ao que foi dito. Na intensificação, que é

\footnotetext{
${ }^{2}$ Este sinal quer dizer seguido de.
} 


\section{Singuagens}

representada pela notação $(\mathrm{x})$, uma oração reforça o significado da outra e "especifica tempo, lugar, causa ou condição" (HALLIDAY; MATTHIESSEN, 2014, p. 493).

Na projeção, segundo Halliday e Matthiessen (2014), a oração secundária é projetada através da oração primária, é representada por aspas, duplas (") para locução e simples (') para ideia. Por meio da projeção, "podemos notar que o processo material abstrato é usado metaforicamente para interpretar fenômenos mentais", isto é, uma oração é representada por meio do conteúdo linguístico (HALLIDAY; MATTHIESSEN, 2014, p. 507). Na sequência, explicamos mais detalhadamente a relação lógico-semântica de projeção.

2.1.2 Relação lógico-semântica de projeção

De acordo com e Halliday e Matthiessen (2014) ${ }^{3}$, projeção é a relação lógicosemântica através da qual a oração passa a funcionar não como uma representação direta da experiência (não linguística), mas como uma representação da representação (linguística). Para os autores, são usos discursivos comuns da projeção: atribuir fontes em notícias, representar pontos de vista no discurso científico, construir diálogo na narrativa, enquadrar questões na conversação. Há três sistemas envolvidos na diferenciação dos tipos de projeção: o nível de projeção (locução ou ideia), o modo de projeção (citação paratática ou relato hipotático), a função de fala (proposição projetada vs. proposta projetada). Segundo Cabral e Barbara (2012),

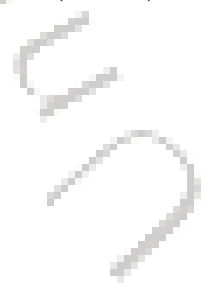

a estrutura hipotática - uso de relatos - e reportar o que e dito por outrem, de modo a passar ao leitor a essência da fala da fonte consultada. Ao contrário, na estrutura paratática - uso de citação - há a apresentação do enunciado da fonte para demonstrar neutralidade (p. 601).

Segundo Halliday e Matthiessen (2014, p. 509), através da projeção, uma oração torna-se a representação do conteúdo linguístico de outra - ou o conteúdo de uma oração verbal de dizer ou o conteúdo de uma oração mental de sentir. Há então dois tipos de projeção. Por um lado, a projeção pode ser a representação do conteúdo de uma oração mental

\footnotetext{
${ }^{3}($ p. 508 e 509)
} 


\section{Singuagens}

- o que é pensado; chamamos essas projeções de ideias. Por outro lado, a projeção pode ser a representação do conteúdo de uma oração verbal - o que é dito; chamamos essas projeções de locuções.

Ainda, segundo os autores, a projeção é representada como um relato ou como citação - algo que é dependente da oração projetante e não pode funcionar isoladamente. A citação e o relato correspondem, respectivamente, ao discurso direto e indireto. Nesse sentido, há dois modos de projeção: parataxe projeta citação e hipotaxe projeta relatos. Ainda há as encaixadas (HALLIDAY; MATTHIESSEN, 2014).

Neste artigo, analisamos a forma mais simples de projeção em que a oração projetante é uma oração de processo verbal, de dizer, e a oração projetada representa o que é dito. Há inúmeros usos desse tipo de nexo de citação - material de testemunhas oculares em notícias, passagens dialógicas em narrativas, cenas em biografia, citações no discurso científico (p.512). Na próxima seção, apresentamos a noção de Atribuição de Martin e White (2005).

\subsection{Expansão dialógica por meio da Atribuição}

Nesta análise, observamos nas notícias os processos verbais recorrentes. De acordo com Cabral e Barbara (2012),

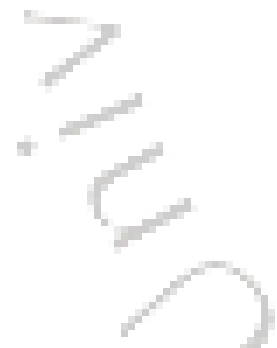
inumeráveis discursos servem-se de orações verbais para promover trocas simbólicas de sentidos e apresentar posicionamentos dialógicos ${ }^{4}$. No discurso jornalístico, tendo em vista a preocupação com o depoimento das fontes, os processos verbais são muito utilizados, o que ocorre frequentemente em noticias ${ }^{5}$ (p. $583)$

Para realizarmos a análise em notícias, buscamos apoio em Martin e White (2005), buscando explicar a relação dialógica que ocorre nas notícias analisadas. Trazemos o subsistema de engajamento que trata de dialogismo e de heteroglossia (BAKHTIN, 2004), pois descreve a forma como pessoas falam, escrevem ou veem discursos de outros, e como

\footnotetext{
${ }^{4}$ Grifo nosso

${ }^{5}$ Idem 3
}

Linguagens \& Cidadania, v. 19, jan./dez., 2017. 


\section{Singuagens}

esses se engajam ou não a esses discursos. Segundo Martin e White (2005, p. 95), o subsistema de engajamento trata da negociação entre enunciador e enunciatário, no que diz respeito ao alinhamento e ao desalinhamento, e de que forma essa negociação interfere no elo entre enunciador e o enunciatário.

De acordo com Martin e White (2005), o subsistema de engajamento é dividido em expansão dialógica e contração dialógica. Com relação à expansão dialógica, o falante/escritor coloca-se aberto, pois convida posicionamentos diferentes do seu. São situações que trazem à base palavras que indicam que a voz autoral é rodeada de muitas possibilidades. Essas ocorrem por acolhimento ou atribuição.

Neste trabalho, consideramos a atribuição, pois por meio do relato e da citação, incluem-se formulações que separam a proposição da voz autoral interna, dando a ela uma voz não autoral. Pode ocorrer por reconhecimento e por distanciamento. A atribuição por reconhecimento que engloba processos verbais que são considerados neutros, que reportam as palavras de outros, principalmente os processos dizer, relatar, declarar (MARTIN; WHITE, 2005, p. 112). Já a atribuição por distanciamento mostra a voz do autor quando relacionadas às vozes não autorais. Ocorre normalmente pelo emprego de citações e de proposições projetas pelos verbos defender, alegar e garantir, dentre outros processos (MARTIN; WHITE, 2005, p. 113).

Esse breve resumo sobre os pressupostos teóricos que embasam a nossa análise, especialmente, o complexo oracional da gramática sistêmico-funcional dado por Halliday (1994) e Halliday e Matthiessen (2004; 2014), serve de referência para a análise da realização lógica da linguagem nos textos que constituem o corpus deste trabalho.

\section{METODOLGIA}

Nesta seção, descrevemos os procedimentos de análise das escolhas linguísticas. Inicialmente, foi feita a segmentação dos complexos oracionais em orações, em seguida, a identificação e a categorização das relações de interdependência (parataxe e hipotaxe) e das relações lógico-semânticas de projeção, juntamente com a análise dos processos verbais. Adotamos a GSF (2014) como base teórica e a noção de atribuição de Martin e White (2005) 


\section{S Linguagens}

para interpretar os dados. Destacamos que, nesta análise, não consideramos as orações encaixadas para a interpretação.

Apresentamos, nesta pesquisa, a análise de duas notícias. Os textos foram publicados em edições online, neste ano, em o jornal Zero Hora do dia 13 de junho e em o jornal $\mathrm{O}$ Estado de S. Paulo, o Estadão, do dia 27 de junho. Destacamos que a edição do jornal Zero Hora menciona o Estadão como "autor” (Por: Estadão Conteúdo). Ambas as notícias são sobre a defesa da presidente Dilma. As notícias serão identificadas por N1 e N2 por ordem cronológica de publicação. Realizamos, manualmente, a análise do complexo oracional e nos detivemos na projeção. Nos fragmentos apresentados, destacamos em negrito os processos examinados.

\subsection{Seleção do corpus}

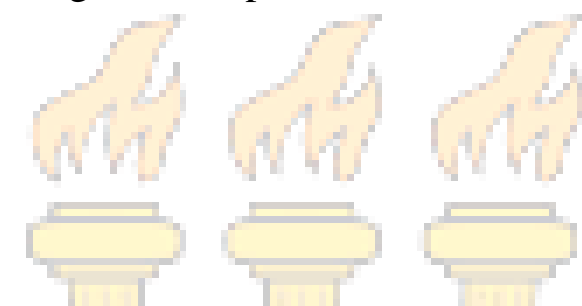

Selecionamos uma notícia anterior à votação do processo de impeachment e outra posterior à data da votação. Em ambas as notícias, a defesa da presidente afastada Dilma apresenta a assertiva de que a votação seria desnecessária, uma vez que a derrota do governo já estaria decidida. Além dos trechos apresentados na análise, trazemos o trecho "Estão usando o processo de impeachment para validar uma decisão que já foi tomada lá atrás." (N2), mais uma vez é possível verificar essa acusação da defesa do governo.

\section{ANÁLISE E DISCUSSÃO DOS DADOS}

Nesta seção, apresentamos a análise e a discussão dos dados. Foram retirados trechos (das duas notícias) que foram selecionados, porque caracterizam os textos selecionados. Nesses trechos, foram considerados, para análise, os processos verbais, especialmente, a projeção e a noção de atribuição de Martin e White (2005). Como é possível observar no trecho da notícia $1(\mathrm{~N} 1)$,

\begin{tabular}{|c|c|c|c|}
\hline \multirow{4}{*}{$\begin{array}{l}\mathrm{N} 1 \\
01\end{array}$} & Número & Estrutura & Oração \\
\hline & 1 & $\alpha$ & |||| Cardozodiz \\
\hline & 2 & “ $\beta$ & ||que direitode defesa de Dilma estásendocerceado || \\
\hline & & & $\alpha^{\wedge " \prime} \beta$ \\
\hline
\end{tabular}

Linguagens \& Cidadania, v. 19, jan./dez., 2017. 


\section{S Linguagens}

No exemplo 01 , a oração projetada " $\beta$ completa o sentido da oração projetante ao trazer o conteúdo que é dito; nesse caso, a projeção de locução é representada como um relato, pois dependente da oração projetante. No exemplo, destacamos a atribuição por reconhecimento, pois engloba o processo verbal dizer que é considerado neutro, uma vez que apenas reporta a palavra de Cardozo.

O autor dessa notícia mostra que, no início do texto, procura apenas relatar aquilo que está noticiando. Para demonstrar isso para o leitor, ele faz uso de um processo verbal neutro. Em contrapartida, nos exemplos 02 e 03 , o autor se utiliza do processo verbal alegar que, de certa forma, traz marcas de autoria relacionadas à voz não autoral.

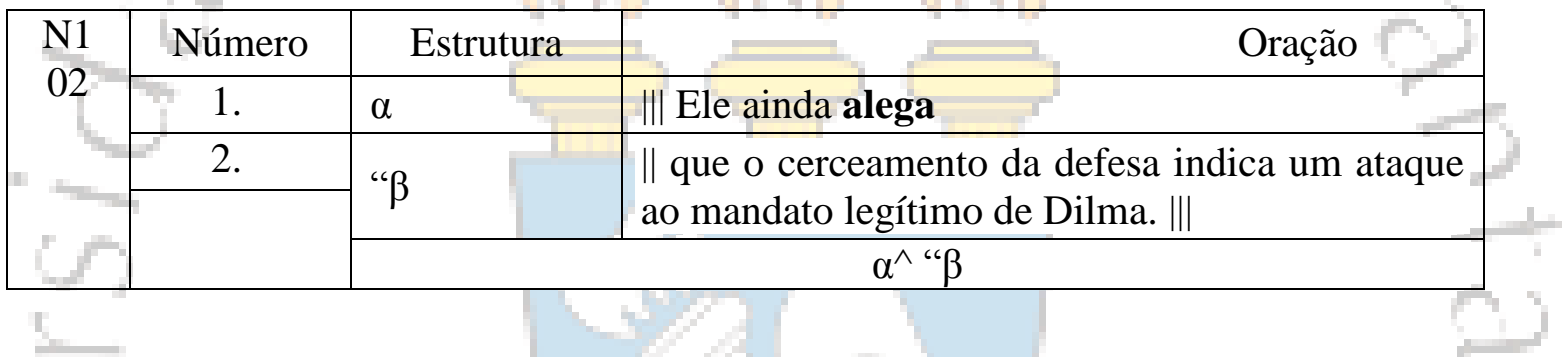

Nos exemplos 02 e 03, os processos verbais alega e alegaram retratam a atribuição por distanciamento, pois mostram a voz do autor, já que, ao escrever alega e alegaram, o autor da notícia deixa marcas de sua opinião contrária ao que está sendo defendido. A atribuição por distanciamento, segundo Martin e White (2015), ocorre normalmente pelo emprego de proposições projetas pelos verbos defender, alegar e garantir, dentre outros (MARTIN e WHITE, 2005, p.113). Nesse trecho, foram trazidas à base palavras que indicam que a voz autoral é rodeada de muitas possibilidades de interpretação.

É possível observar que, no trecho 03 , há, de forma implícita, uma denúncia, pois, ao usar a modalização poderia e o processo material comprometer, o autor apresenta a ideia de prejuízo para o processo de votação de impeachment.

\begin{tabular}{|c|c|c|c|c|}
\hline \multirow{3}{*}{$\begin{array}{l}\text { N1 } \\
03\end{array}$} & 1. & \multicolumn{2}{|r|}{$\alpha$} & ||| Os parlamentares alegaram \\
\hline & 2. & \multirow{2}{*}{$" \beta$} & 1 & || que a medida não acrescentaria novas informações \\
\hline & 3. & & +2 & $\begin{array}{l}\text { \| e que poderia comprometer o cronograma do } \\
\text { processo. }\|\|\end{array}$ \\
\hline
\end{tabular}

Linguagens \& Cidadania, vo 19, jan./dez., 2017. 


\section{S Linguagens}

$\alpha^{\wedge ‘ ‘} \beta\left(1^{\wedge}+2\right)$

Ainda com relação ao exemplo 03, considerando a noção de atribuição Martin e White (2015), na oração projetada “ $\beta$, o processo material acrescentaria e a modalização poderia seguida do processo material comprometer mostram a atribuição por distanciamento do autor do texto com relação ao que está sendo dito.

Similar a 3, no exemplo 04 , trecho da N2, a oração $\alpha$ projeta e a oração " $\beta$ caracterizam um relato, nesse caso, é reforçada a neutralidade do processo verbal chegou a dizer (disse), pois mostra a opinião do senador Álvaro Dias (PV-PR), que era favorável ao impeachment, mas não mostra a autoria de quem escreve o texto.

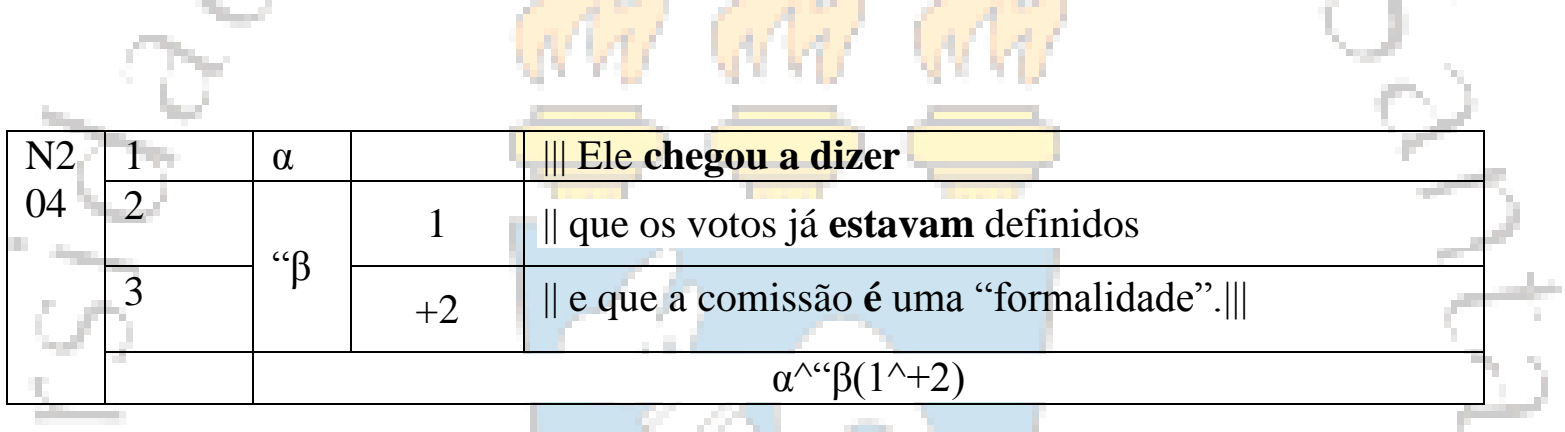

Outra construção nas notícias analisadas é a citação. Trazemos no exemplo 05, que é um simplex, a oração 1 projetada parataticamente pela oração 2 , o que significa que a projeção é representada como uma citação. Nesse caso, as formulações separam a proposição da voz autoral interna, dando a ela uma voz não autoral.

De acordo com Halliday e Matthiessen (2014), essa é a forma mais simples de projeção. Nesse excerto, mais uma vez a oração 1 é projetada parataticamente pela oração 2, a citação está entre aspas.

\begin{tabular}{|c|c|c|c|}
\hline \multirow{4}{*}{$\begin{array}{c}\mathrm{N} 2 \\
05\end{array}$} & Número & Estrutura & Oração \\
\hline & 1 & 1 & $\begin{array}{l}\text { III "A fase de depoimentos foi cansativa e } \\
\text { improdutiva em grande parte. Isso porque muitas } \\
\text { testemunhas foram escolhidas pela defesa sem } \\
\text { nenhum conhecimento, com caráter } \\
\text { procrastinador", }\end{array}$ \\
\hline & 2 & 2 & $\begin{array}{l}\| \text { - afirmou o líder do Democratas, Ronaldo } \\
\text { Caiado (GO).\|\| }\end{array}$ \\
\hline & & & \\
\hline
\end{tabular}

Linguagens \& Cidadania, vo 19, jan./dez., 2017. 


\section{S Linguagens}

Já, no exemplo 06, o mesmo processo verbal afirmou, a oração " $\beta$ é projetada hipotaticamente pela oração $\alpha$, o que evidencia que a projeção é representada como um relato.

\begin{tabular}{|c|c|c|c|}
\hline \multirow{3}{*}{$\begin{array}{l}\mathrm{N} 2 \\
06\end{array}$} & Número & Estrutura & Oração \\
\hline & 1 & $\alpha$ & $\begin{array}{l}\text { IIE Em uma das sessões, o senador Álvaro Dias (PV- } \\
\text { PR), favorável ao impeachment, afirmou }\end{array}$ \\
\hline & 2 & " $\beta$ & \| que o processo é "protelatóric \\
\hline
\end{tabular}

Ao final da análise e da discussão, compreendemos que as relações semânticas promovem a coesão natural da língua. Como observamos no artigo, um dos aspectos nesta interpretação foi o sistema lógico-semântico que diz respeito às relações semântico-funcionais que acontecem entre as orações que integram orações complexas. Observamos também que as relações lógico-semânticas abrangem dois tipos de relações, a saber, a expansão e a projeção. Verificamos que nossa análise mostrou a projeção-locução com mais ênfase no modo hipotático.

\section{CONSIDERAÇÕES FINAIS}

Buscamos, nesta análise, observar como ocorrem os processos de atribuição em duas notícias de jornais online tendo em vista a relação lógico-semântica de projeção. Constatamos a interdependência hipotática, representada pelas letras gregas $\alpha$ e $\beta$, de forma mais recorrente. Por se tratar de um jornal contrário ao governo (NUNES, 2014), as orações são projetadas por processos verbais que trazem marcas de autoria relacionadas às vozes não autorais, como é o caso de alegar. Também foram usados pelos autores processos neutros como é o caso de dizer quando queriam apenas relatar a informação ou fato.

Considerando a análise nas duas notícias de forma geral, podemos dizer que, levando em consideração os estudos de Halliday e Matthiessen (2014), as orações projetadas em questão completam o sentido de uma oração projetante que completa uma ideia de locução 


\section{Singuagens}

(dizer), no caso, as projeções. A ocorrência dessa relação lógico-semântica caracteriza a existência de complexos oracionais ligados de forma paratática ou hipotática. Essa relação pode ocorrer com atribuição por reconhecimento ou distanciamento. Essa distinção é caracterizada, normalmente, pelo emprego dos processos verbais.

\section{REFERÊNCIAS}

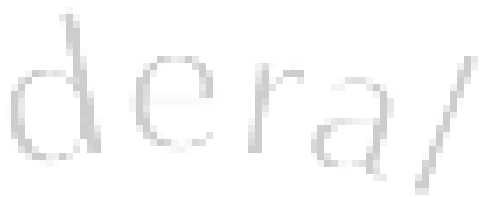

BAKHTIN, M. Marxismo e filosofia da linguagem. 11. ed. São Paulo: Hucitec, 2004.

BARBARA, L.; MACEDO, C. M. M. Artigos acadêmicos em revistas de prestígio: forma da mensagem como processo verbal. Apresentado no V Congresso Internacional de La Asociación de Linguística Sistémico-Funcional. Mar Del Plata, Argentina, 2009.

BARBARA, L.; CABRAL, S, R. Processos verbais no discurso jornalístico: frequência e organização da mensagem. São Paulo, DELTA, 2012.

FARENCENA, G. S. Artigo de opinião como macrogênero: relações lógico-semânticas na perspectiva sistêmico-funcional. Santa Maria: UFSM, 2016. Tese (Doutorado em Letras), UNIVERSIDADE FEDERAL DE SANTA MARIA, Santa Maria, 2016.

HALLIDAY, M. A.K. An introduction to functional grammar. 2. ed. London: Arnold, 1994.

HALLIDAY, M. A. K; MATHIESSEN C. M. I. M. An introduction to function grammar. 4. ed. London: Routledge, 2014.

MARTIN, J.; WHITE, P. The language of evaluation: appraisal in English. New York, NY/USA: Palgrave, 2005.

NUNES, G. G. O Estadão e a presidente: o editorial como forma de avaliação. Santa Maria: UFSM, 2014. Dissertação (Mestrado em Letras), UNIVERSIDADE FEDERAL DE SANTA MARIA, Santa Maria, 2014.

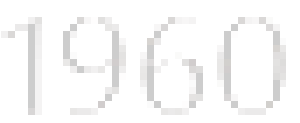




\section{Linguagens}

\section{ANEXOS}

\section{ANEXO 1 - Notícia 1- N1}

\begin{tabular}{|c|c|lc|}
\hline Número & Estrutura & \multicolumn{1}{c|}{ Oração } \\
\hline 1 & $\alpha$ & |||| Cardozodiz & \\
\hline 2 & " $\beta$ & ||quedireitodedefesadeDilma estásendocerceado || & \\
& & & $\alpha$ " $\beta$
\end{tabular}

\begin{tabular}{|c|c|c|}
\hline Número & Estrutura & Oração \\
\hline 1. & $\alpha$ & ||| Ele alega \\
\hline $1 x^{2}$ & " $\beta$ & $\begin{array}{l}\text { \|l que [[quem está por trás das negativas da comissão do } \\
\text { impeachment]] tem "medo [[de que se prove a inconsistência das } \\
\text { provas por crime de responsabilidade fiscal]]" }\end{array}$ \\
\hline & & $\alpha^{\wedge \ltimes "} \beta[[]][[]]$ \\
\hline
\end{tabular}

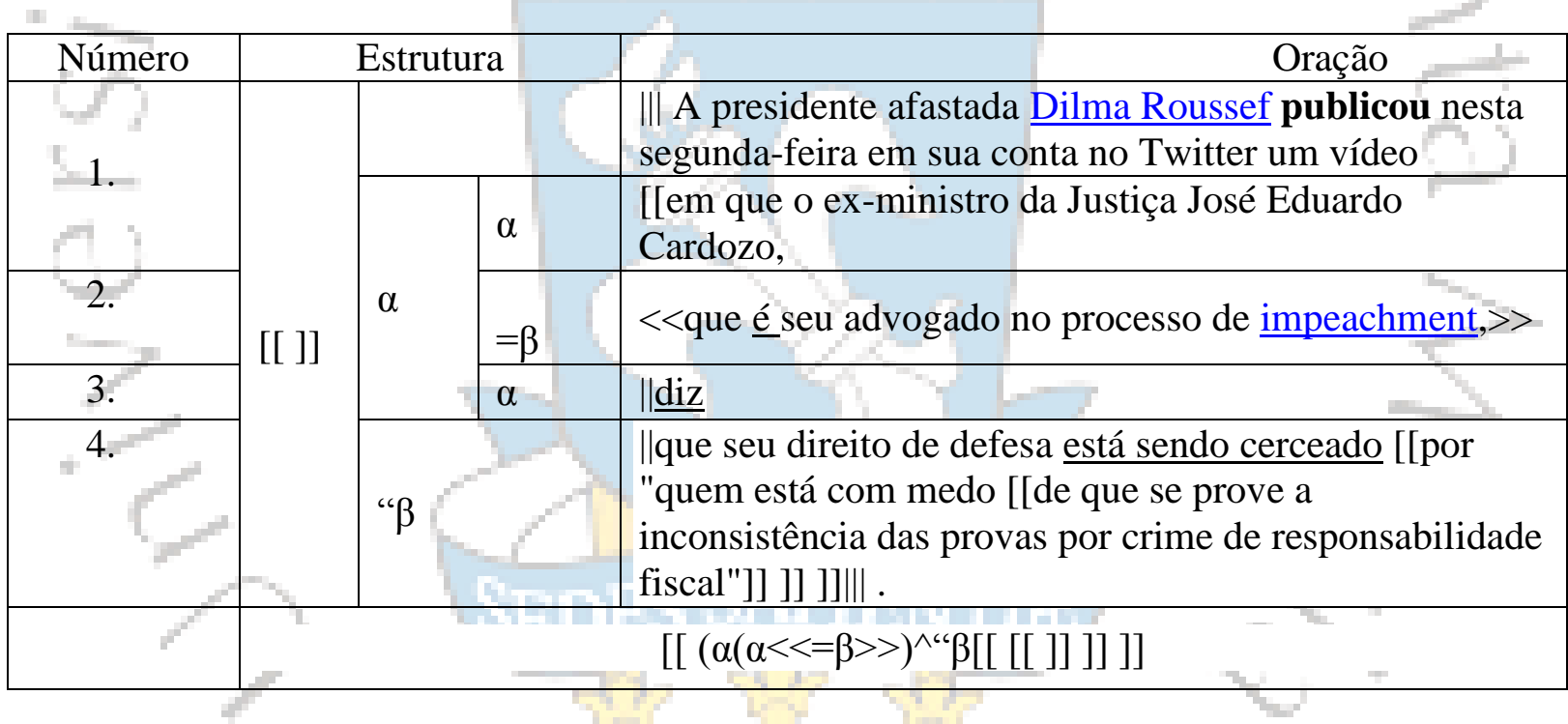

\begin{tabular}{|c|c|}
\hline$[[[[[[]]]]]$ & $\begin{array}{l}\text { ||| A presidente afastada Dilma Roussef publicou nesta segunda-feira em sua } \\
\text { conta no Twitter um vídeo [[em que o ex-ministro da Justiça José Eduardo } \\
\text { Cardozo, } \| \text { que é seu advogado no processo de impeachment, \|diz que seu } \\
\text { direito de defesa está sendo cerceado por "quem [[está com medo [[de que se } \\
\text { prove a inconsistência das provas por crime de responsabilidade fiscal"]] ]] } \\
\text { ]]\|. SIMPLEXO }\end{array}$ \\
\hline
\end{tabular}

\begin{tabular}{|c|l|lc|}
\hline Número & Estrutura & \multicolumn{1}{c|}{ Oração } \\
\hline 1. & $\alpha$ & $\|$ Cardozo apontou $\|$ & \\
\hline
\end{tabular}

Linguagens \& Cidadania, v. 19, jan./dez., 2017. 


\section{Linguagens \& Cidadania}

\begin{tabular}{|c|c|c|}
\hline \multirow[t]{2}{*}{2.} & $" \beta[[]]^{\wedge}[[]]$ & $\begin{array}{l}\text { ||| que [[o indeferimento de testemunhas de defesa [[que } \\
\text { seriam ouvidas na comissão do impeachment, como os ex- } \\
\text { ministros Bresser Pereira e Ciro Gomes]]]], e do pedido de } \\
\text { perícia técnica demonstram [[que o direito de defesa } \\
\text { garantido pela Constituição Federal está sendo atingido]]. ||| }\end{array}$ \\
\hline & \multicolumn{2}{|r|}{$\alpha^{\alpha^{\wedge c} \beta} \beta[[]]^{\wedge}[[]]$} \\
\hline Número & Estrutura & Oração \\
\hline 1. & \multirow[b]{2}{*}{ [[ ]] } & \multirow{2}{*}{$\begin{array}{l}\text { || Segundo ele, políticos e juristas [[que poderiam indicar a } \\
\text { inconsistência jurídica das acusações]] deveriam ser } \\
\text { ouvidos. } \mid \| \\
\text { simplex }\end{array}$} \\
\hline 2. & & \\
\hline
\end{tabular}

\begin{tabular}{|c|c|c|}
\hline 1. & $y^{2}$ & || Do mesmo modo, ele afirmou \\
\hline 2. & & || que a situação técnica das denúncias é complexa \\
\hline 3. & $\beta$ & || e que peritos têm que analisar os argumentos. ||| \\
\hline$t^{-1}$ & & $\alpha^{\wedge} \beta\left(1^{\wedge}+2\right)$ \\
\hline
\end{tabular}

\begin{tabular}{|r|l|l|l|}
\hline 1. & $\alpha$ & & $\|||$ O ex-ministro ainda frisou \\
\hline 2. & \multirow{2}{*}{$*$} & 1 & $\begin{array}{l}\| \text { que o relator do processo, senador Antonio Anastasia (PSDB-MG), } \\
\text { era a favor do trabalho }\end{array}$ \\
\cline { 3 - 4 } & & +2 & $\|$ e que foi a comissão [[que decidiu por indeferir o pedido]] $\mid \|$ \\
\hline 3. & \multicolumn{3}{|c|}{$\alpha^{\wedge "} \beta\left(1^{\wedge}+2\right)$} \\
\hline
\end{tabular}

\begin{tabular}{|c|c|c|c|}
\hline 4. & & $\|$ Segundo Cardozo, a perícia provaria a inocência de Dilma. \|\| \\
Simplex
\end{tabular}

\begin{tabular}{|c|c|c|}
\hline Número & Estrutura & Oração \\
\hline \multirow{2}{*}{1.} & & $\begin{array}{l}\text { III - Não tenho a menor dúvida [[que uma perícia isenta } \\
\text { demonstrará a clara correção de comportamento do governo, }\end{array}$ \\
\hline & $=\beta$ & $\begin{array}{l}\text { \|comandado pela presidente Dilma Roussef, } \| \text { tanto nos } \\
\text { decretos de abertura de créditos suplementares quanto nas } \\
\text { chamadas pedaladas fiscais no ano de } 2015]]-\end{array}$ \\
\hline \multirow[t]{2}{*}{2.} & 2 & $\|$ - afirmou $\|$ \\
\hline & \multicolumn{2}{|r|}{$" 1[[\alpha=\beta]]^{\wedge} 2$} \\
\hline
\end{tabular}

\begin{tabular}{|l|l|l|}
\hline Número & \multicolumn{1}{|c|}{ Estrutura } & \multicolumn{1}{c|}{ Oração } \\
\hline 1 & $\alpha$ & $\| \mid$ Ele ainda alega \\
\hline 2 & “ $\beta$ & $\begin{array}{l}\| \text { que o cerceamento da defesa indica um ataque ao mandato } \\
\text { legítimo de Dilma. } \|\end{array}$ \\
\hline
\end{tabular}

Linguagens \& Cidadania, v. 19, jan./dez., 2017. 


\section{Linguagens \& Cidadania}

\section{$\alpha^{\wedge} " \beta$}

\begin{tabular}{|c|c|c|}
\hline Número & Estrutura & Oração \\
\hline 1. & \multirow{3}{*}[[[[]]^{\wedge}[[]]]]{} & \multirow{3}{*}{$\begin{array}{l}\text { || Estamos mostrando para o Brasil e para o mundo [[que } \\
\text { realmente não estamos diante de um processo de impeachment } \\
\text { [[que acontece de acordo com a Constituição]], mas sim [[que } \\
\text { estamos diante de um golpe de Estado]] ]]. }\|\|\end{array}$} \\
\hline 2. & & \\
\hline 3. & & \\
\hline
\end{tabular}

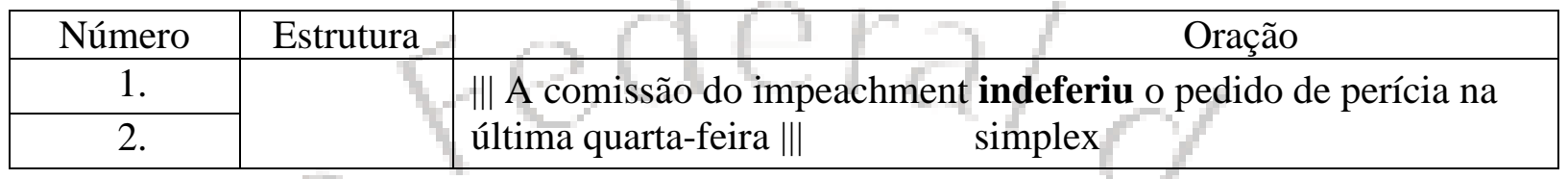

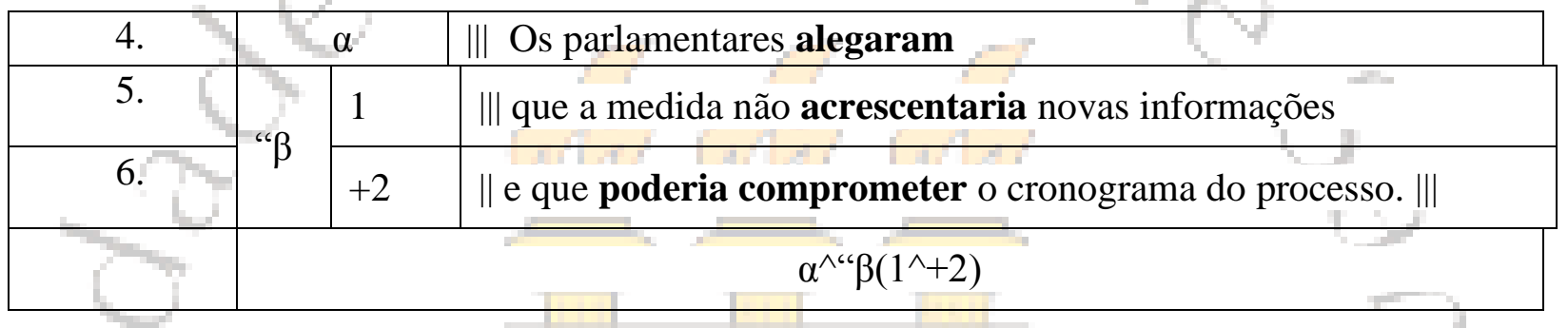

\begin{tabular}{|c|c|l|}
\hline 1. & {$[[]]$} & $\begin{array}{l}|| \mid \text { No caso das testemunhas, somente } 15 \text { dos } 40 \text { nomes [[apresentados } \\
\text { pela defesa]] foram aceitos }|| \mid \quad \text { simplex }\end{array}$ \\
\hline
\end{tabular}

\begin{tabular}{|c|l|l|}
\hline 1. & $\alpha$ & $\|$ Anastasia afirmou\| \\
\hline 2. & “ $\beta[[]]$ & $\begin{array}{l}\| \text { que só ouviria pessoas [[que tivessem relação com os fatos } \\
\text { apresentados]]\|. }\end{array}$ \\
\hline & \multicolumn{4}{|c|}{$\alpha^{\wedge} " \beta[[]]$} \\
\hline
\end{tabular}

http://zh.clicrbs.com.br/rs/noticias/politica/noticia/2016/06/cardozo-diz-que-direito-de-defesade-dilma-esta-sendo-cerceado-5980111.html

Por: Estadão Conteúdo 13/06/2016 - 19h39min

\section{ANEXO 2 - Notícia 2 N2}

\section{Aliados de Dilma acusam Senado de 'desinteresse'}

Com ausência de parlamentares durante depoimentos e dispensa de testemunhas, Casa encerra quarta-feira a fase probatória do processo de impeachment.

\begin{tabular}{|c|c|c|}
\hline Número & Estrutura & Oração \\
\hline 1 & 1 & $\| \mid$ Com parlamentares dando sinais de desinteresse após 11 \\
\hline
\end{tabular}

Linguagens \& Cidadania, v. 19, jan./dez., 2017. 


\section{Linguagens \& Cidadania}

\begin{tabular}{|l|l|l|}
\hline & & reuniões [[para ouvir testemunhas]], \\
\hline 2 & $\mathrm{x} 2$ & $\begin{array}{l}\| \text { o Senado deve encerrar na quarta-feira a fase probatória do } \\
\text { processo de impeachment da presidente afastada Dilma Rousseff. } \mid \|\end{array}$ \\
\hline & \multicolumn{2}{|c|}{$\left(1^{\wedge} \times 2\right)$} \\
\hline
\end{tabular}

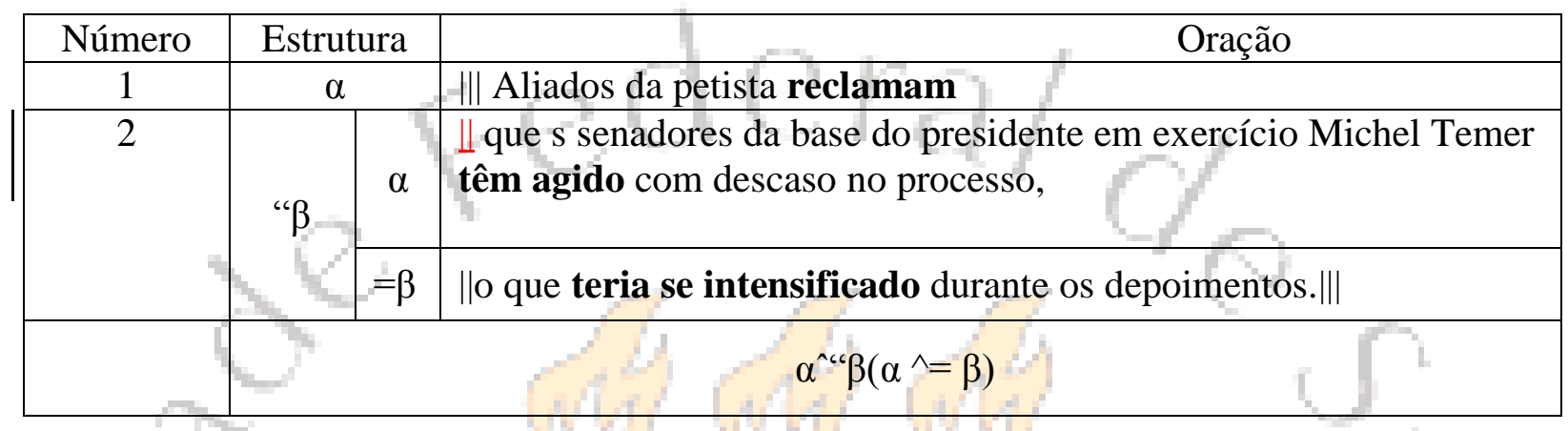

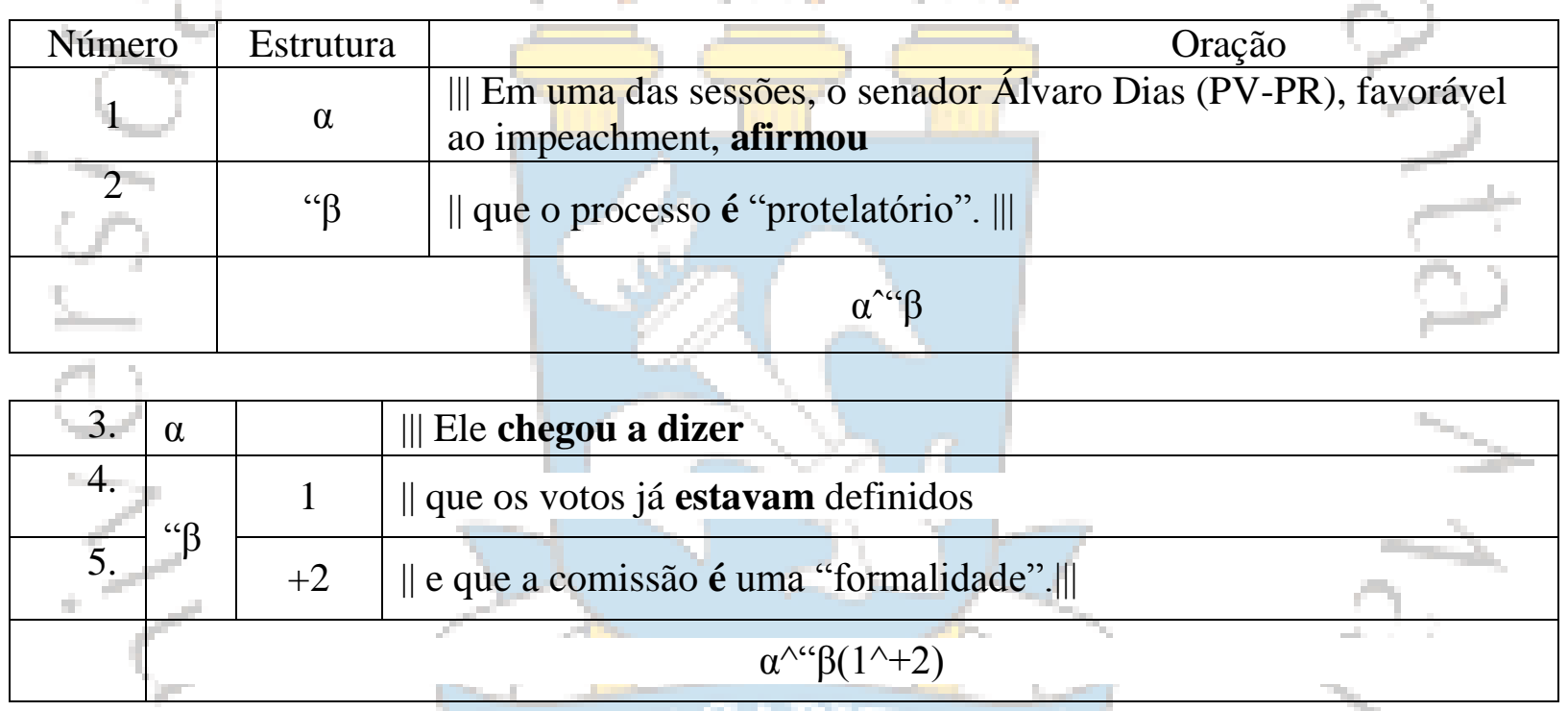

\begin{tabular}{|c|c|l|}
\hline Número & Estrutura & \multicolumn{1}{c|}{ Oração } \\
\hline 1 & 1 & $\|$ Também houve grande número de ausências - \\
\hline & $=2[[]]$ & $\begin{array}{l}\| \text { por duas vezes, o quórum da comissão caiu quase a ponto [[de a } \\
\text { reunião ser suspensa]]. } \|\end{array}$ \\
\hline & \multicolumn{3}{|c|}{$\left(1^{\wedge}=2[[]]\right)$} \\
\hline
\end{tabular}

\begin{tabular}{|r|l|l|l|}
\hline 1. & $\mathrm{x} \beta$ & & $\begin{array}{l}\| \text { Para haver sessão Coordenada pela senadora Simone Tebet (PMDB- } \\
\text { MS), }\end{array}$ \\
\hline 2. & $\alpha$ & 1 & $\begin{array}{l}\| \text { a base aliada de Temer abriu mão [[de fazer perguntas às } \\
\text { testemunhas]] }\end{array}$ \\
\hline
\end{tabular}

Linguagens \& Cidadania, v. 19, jan./dez., 2017. 


\section{Linguagens \& Cidadania}

\begin{tabular}{|c|c|c|}
\hline 3. & +2 & $\|$ chegou a aprovar a dispensa de testemunhas de acusação. $\|$ \\
\hline & \multicolumn{2}{|c|}{} \\
\hline
\end{tabular}

\begin{tabular}{|c|c|c|c|c|}
\hline 1. & \multirow{3}{*}{ “ $\beta$} & \multicolumn{2}{|c|}{1} & $\begin{array}{l}\text { III "Esse é o único processo [[que eu conheço]] [[em que a acusação } \\
\text { abre mão de produzir provas]]. }\end{array}$ \\
\hline 2. & & \multirow[b]{2}{*}{+2} & $\alpha$ & || Mas eles não podem interrogar as testemunhas \\
\hline 3. & & & $x \beta$ & III porque estariam produzindo provas contra eles mesmos", \\
\hline \multirow[t]{2}{*}{4.} & $\alpha$ & & & $\begin{array}{l}\| \text { disse a senadora Vanessa Grazziotin (PC do B-AM), membro da } \\
\text { tropa de choque de Dilma na comissão. } \|\end{array}$ \\
\hline & & & & $“ \beta\left(1[[]]^{\wedge}[[]]^{\wedge}+2\left(\alpha^{\wedge} x \beta\right)\right)^{\wedge} \alpha$ \\
\hline
\end{tabular}

|| Senadores da base questionam a quantidade [[de depoentes trazidos pela defesa - ao todo, 40]].||

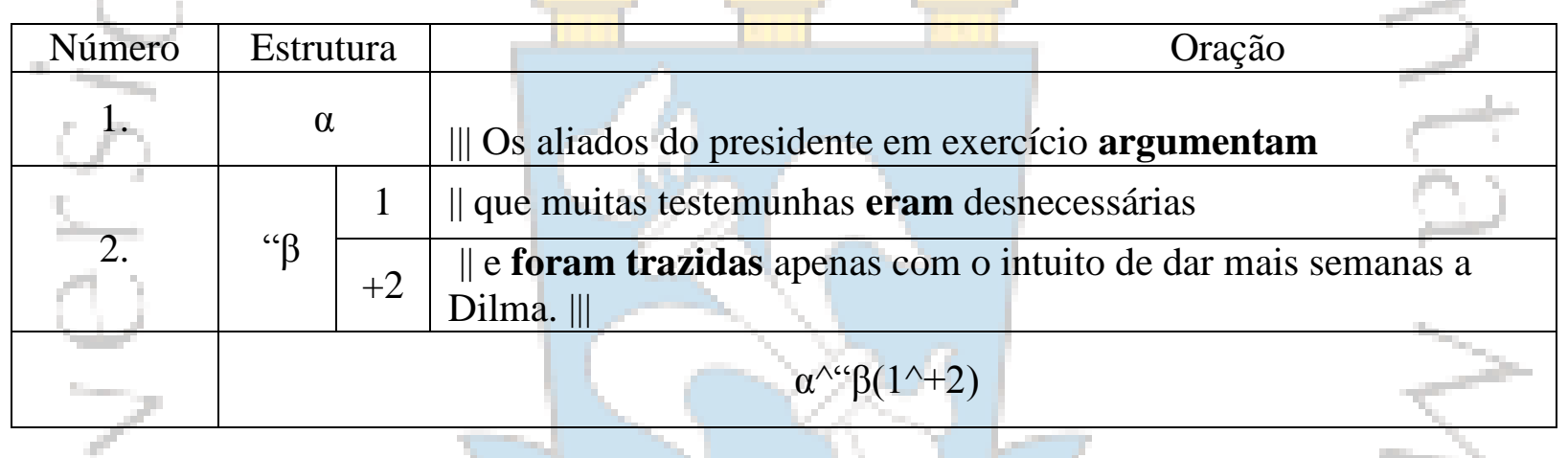

\begin{tabular}{|c|c|c|}
\hline $\begin{array}{l}\text { Núme } \\
\text { ro }\end{array}$ & & Oração \\
\hline \multirow{2}{*}{3.} & $\alpha$ & $\begin{array}{l}\text { ||| "A fase de depoimentos foi cansativa e improdutiva em grande } \\
\text { parte. }\end{array}$ \\
\hline & $x \beta$ & $\begin{array}{l}\text { \|Isso porque muitas testemunhas foram escolhidas pela defesa sem } \\
\text { nenhum conhecimento, com caráter procrastinador", }\end{array}$ \\
\hline 4. & $\alpha$ & $\|$ — afirmou o líder do Democratas, Ronaldo Caiado (GO). \|\| \\
\hline & & " $\beta\left(\alpha^{\wedge} \times \bar{x}\right)^{\wedge} \alpha$ \\
\hline
\end{tabular}

\begin{tabular}{|c|c|c|c|c|}
\hline 1. & \multicolumn{3}{|l|}{1} & ЩPara Vanessa, porém, há desinteresse. \\
\hline 2. & $=2$ & 1 & $\alpha$ & ||“Eles (a oposição) não têm nenhum pudor [[de dizer \\
\hline
\end{tabular}

Linguagens \& Cidadania, v. 19, jan./dez., 2017. 


\section{S. Linguagens}

\begin{tabular}{|c|c|c|c|}
\hline 3. & & & ||que já está definido, \|| que é uma formalidade]] \\
\hline 4. & & $x \beta$ & || porque não se interessam pelas respostas \\
\hline 5 . & & $\alpha$ & \|Estão usando o processo de impeachment \\
\hline 6. & $=2$ & $x \beta$ & $\begin{array}{l}\text { "| para validar uma decisão que já foi tomada lá } \\
\text { atrás.”|| }\end{array}$ \\
\hline
\end{tabular}

\begin{tabular}{|c|c|c|}
\hline 1. & 1 & $\begin{array}{l}\text { ॥ Ao longo das três semanas de depoimentos, a tropa de choque de } \\
\text { Dilma também demonstrou desgaste }\end{array}$ \\
\hline 2. & $\alpha$ & \| e chegou a negociar, por duas vezes, um acordo de procedimento \\
\hline 3. & $x \beta$ & \|para liberar as testemunhas mais rapidamente $\|$ \\
\hline & & $1^{\wedge}+2\left(\alpha^{\wedge} x \beta\right)$ \\
\hline
\end{tabular}

\begin{tabular}{|c|c|c|c|c|}
\hline 1. & \multicolumn{2}{|l|}{1} & $\begin{array}{l}\text { \| Nos bastidores, os petistas assumem a dificuldade } \\
\text { [[de reverter votos na comissão]] }\end{array}$ & 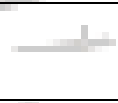 \\
\hline 2. & \multirow[b]{2}{*}{+2} & $\alpha$ & $\|$ e acreditam & 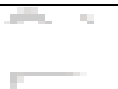 \\
\hline & & ' $\beta$ & $\begin{array}{l}\text { " que o placar pode estar definido: } 15 \text { a } 5 \text { a favor do afastamen } \\
\text { como na primeira fase. } \|\end{array}$ & to, \\
\hline 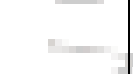 & & & $1^{\wedge}+2\left(\alpha^{\wedge} \beta\right)$ & \\
\hline
\end{tabular}

Isabela Bonfim, Julia Lindner - O Estado de S.Paulo 27 Junho 2016

http://politica.estadao.com.br/noticias/geral,aliados-de-dilma-acusam-senado-dedesinteresse, 10000059420 